\title{
Trapeziometacarpal total joint arthroplasty: The effect of capsular release on range of motion
}

\section{L'effet de la libération capsulaire sur la mobilité des prothèses trapézo-métacarpiennes}

\author{
B. Van Hove ${ }^{a}$, J. Vantilt ${ }^{\mathrm{b}}$, A. Bruijnes ${ }^{\mathrm{b}}$, P. Caekebeke ${ }^{\mathrm{a}}$, K. Corten $^{\mathrm{a}}$, I. Degreef $^{\mathrm{c}}$, \\ J. Duerinckx ${ }^{\mathrm{a}, *}$ \\ ${ }^{a}$ Department of Orthopedic Surgery and Traumatology, Ziekenhuis Oost-Limburg, Schiepse Bos 6, 3600 Genk, Belgium \\ ${ }^{\mathrm{b}}$ Orthopedic Research Foundation Genk vzw, Ziekenhuis Oost-Limburg, Schiepse Bos 6, 3600 Genk, Belgium \\ ${ }^{\mathrm{c}}$ Department of Orthopedic Surgery, UZ Leuven, Herestraat 49, 3000 Leuven, Belgium
}

\section{A R T I C L E I N F O}

\section{Article history:}

Received 1st April 2020

Received in revised form 25 April 2020

Accepted 27 April 2020

Available online $\mathrm{xxx}$

\section{Keywords:}

Trapeziometacarpal

Arthroplasty

Neck

Capsule

Motion

Dislocation

\begin{abstract}
A B S T R A C T
It has been suggested that trapeziometacarpal total joint arthroplasty be combined with complete release of the joint capsule to prevent ligament tethering and implant dislocation. Our goal was to evaluate the consequences of capsular release on range of motion. Trapeziometacarpal joint motion was measured with a 3D motion tracking system in seven fresh frozen human cadaver hands before and after capsular release and total joint arthroplasty with subsequently longer neck lengths. Relative to the native trapeziometacarpal joint with intact joint capsule, mean flexion-extension was significantly increased after the arthroplasty with released capsule and lengthening up to $6 \mathrm{~mm}$. Mean abductionadduction did not increase significantly. Total joint replacement combined with capsular release increases the trapeziometacarpal joint's range of motion, but not beyond the limits of most trapeziometacarpal implant designs. Lengthening of the implant neck progressively decreases the excess motion.
\end{abstract}

(c) 2020 SFCM. Published by Elsevier Masson SAS. All rights reserved.

\section{R É S U M É}

L'association d'un remplacement total de l'articulation trapézo-métacarpienne avec une libération capsulaire complète a été suggérée pour empêcher des luxations. Notre objectif était d'évaluer les conséquences de la libération capsulaire sur l'amplitude de mouvement. Les mouvements de l'articulation trapézo-métacarpienne ont été mesurés avec un détecteur de mouvement 3D sur sept mains cadavériques humaines fraîches congelées. Les mesures ont été faites avant et après la libération capsulaire et le remplacement total de l'articulation avec des cols de longueur progressivement croissante. Par rapport à l'articulation trapézo-métacarpienne normale avec capsule articulaire intacte, le mouvement moyen de flexion-extension a été significativement augmenté pour la prothèse avec libération capsulaire et allongement jusqu'à $6 \mathrm{~mm}$. Le mouvement moyen d'abduction-adduction n'a pas été significativement augmenté. Une prothèse trapézo-métacarpienne, associée à une libération capsulaire, augmente l'amplitude de mouvement de l'articulation trapézo-métacarpienne, mais pas audelà des limites de la plupart des modèles de prothèses. L'allongement du col prothétique diminue progressivement l'excès de mouvement.

(c) 2020 SFCM. Publié par Elsevier Masson SAS. Tous droits réservés.

\footnotetext{
* Corresponding author. Ziekenhuis Oost-Limburg, Schiepse Bos 6, 3600 Genk, Belgium.

E-mail address: joris.duerinckx@gmail.com (J. Duerinckx).
} 


\section{Introduction}

One of the surgical treatment options for trapeziometacarpal (TMC) osteoarthritis is total joint arthroplasty (TJA) with a ball-insocket joint implant. Despite reports of early postoperative improvement of thumb motion, strength and pain [1-3], the 5\% dislocation rate remains a concern [4]. Dislocations can be caused by incorrect component positioning [5] or inadequate soft tissue balancing [6]. Ligament imbalance can develop when the native saddle joint with its complex biomechanics [7] is replaced by a prosthetic joint with a single center of rotation. This led to the suggestion that TJA surgery be combined with complete release of the TMC joint capsule to prevent ligament tethering. However, the resulting decrease in soft tissue tension can increase motion and the risk of dislocation early in the postoperative period before capsular scarring has occurred [6].

The purpose of this study was to examine the effect of capsular release and TJA on range of motion (ROM) of the TMC joint. We hypothesized that complete capsular release and TJA would increase ROM and that progressive lengthening of the implant's neck would again decrease ROM.

\section{Material and methods}

Seven fresh frozen human cadaver forearms (3 right and 4 left, 2 male and 5 female) were thawed at room temperature. The mean age of the specimen was 82.5 years (range 73-89). Institutional ethics committee approval was obtained (CME 2018/081).

\subsection{Experimental setup}

Fingers 2-5 were disarticulated at the metacarpophalangeal joint. Both forearm bones and the second and fourth metacarpals were attached to a wooden plate using plastic fasteners and installed on a wooden table. This ensured a fixed reference frame for TMC joint motion. A strand of 2-0 Prolene ${ }^{\mathrm{TM}}$ (Ethicon ${ }^{\mathbb{R}}$, Johnson \& Johnson, Somerville, NJ, USA) was attached to each of the four extrinsic tendons of the thumb (extensor pollicis longus, extensor pollicis brevis, abductor pollicis longus and flexor pollicis longus) at the forearm. Similarly, a strand of 2-0 Prolene was attached to the abductor pollicis brevis insertion on the radial sesamoid at the metacarpophalangeal joint, and the adductor pollicis insertion on the ulnar sesamoid. Pulleys on the testing jig were used to align each strand with the direction of pull of the corresponding muscle. The tendons around the thumb were each loaded with $100 \mathrm{~g}$ in order to simulate physiological muscle tone and to induce compression across the TMC joint [8]. We used a threedimensional motion tracking system (Patriot ${ }^{\mathrm{TM}}$ system, Polhemus Inc. ${ }^{\circledR}$, Colchester, VT, USA) to assess TMC joint motion. This system includes a short-range $(2.5$ to $60.9 \mathrm{~cm})$ magnetic field transmitter, fixed on the horizontal surface of the testing jig, and two sensors. Sensor S1 was a $1.8 \mathrm{~mm}$ microsensor that was placed in a drill hole in the proximal part of the trapezium. Sensor S2 was a standard sensor that was fixed on the first metacarpal head with two plastic screws (Fig. 1). The system measures motion of both sensors in six degrees of freedom simultaneously. It has an accuracy of $0.15^{\circ}$ for spatial orientation and $0.08 \mathrm{~mm}$ for position.

\subsection{Variables}

Every specimen was tested in the following configurations of the TMC joint: (1) normal joint; (2) normal joint after complete capsular release through a palmar approach; and (3) after TJA. Before the TJA, a parallel saw blade with a width of $5 \mathrm{~mm}$ was used to remove both the trapezial and metacarpal articular surfaces as

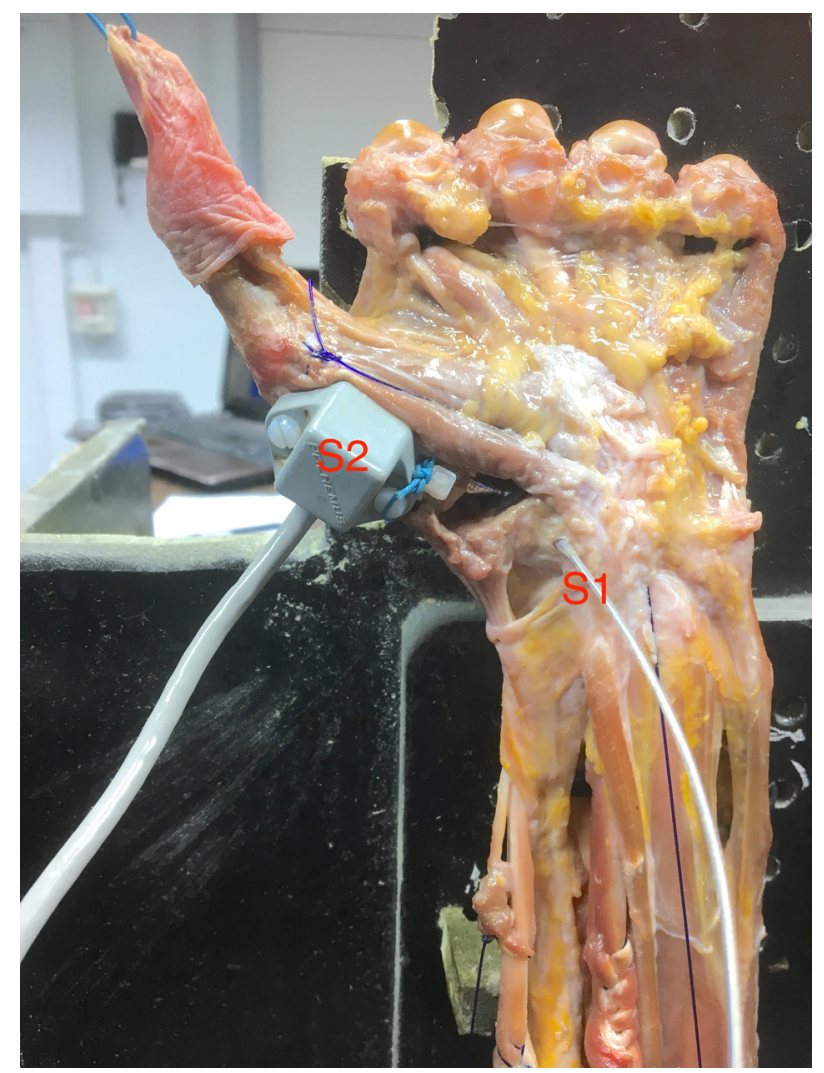

Fig. 1. Palmar view of the trapeziometacarpal joint after total joint arthroplasty. Sensor 1 (S1) was inserted in a drill hole in the trapezium. Sensor $2(S 2)$ was fixed on the head of the first metacarpal with plastic screws.

one piece. Next, an Arpe ${ }^{\mathrm{TM}}$ prosthesis (Zimmer Biomet ${ }^{\mathbb{R}}$, Warsaw, Indiana, USA) was implanted with the stem in the first metacarpal and the $9 \mathrm{~mm}$ non-constrained cup in the trapezium. This ball-andsocket implant has a range of motion of $100^{\circ}$. Care was taken to impact both components exactly to the level of bone resection. The implant was then completed with a $0 \mathrm{~mm}$ long offset neck. This neck length perfectly filled the gap left by the saw blade (Fig. 2). This ensured the normal length of the TMC joint was restored. Subsequently longer necks were tested in $2 \mathrm{~mm}$ increments up to $8 \mathrm{~mm}$.

Active ROM of the thumb was simulated in four directions (flexion, extension, abduction, adduction) by differential loading of the intrinsic and extrinsic muscles. The amount of load was proportional to the muscle's cross-sectional area [8]. Each test was performed five consecutive times.

\subsection{Data sampling and analysis}

The data were segmented by splitting the thumb's motion in two planes, i.e. flexion-extension and abduction-adduction. Positional data for the S1 sensor in the trapezium was used as a reference to correct for any micromotion of the trapezium during thumb motion. Positional data from the S2 sensor on the first metacarpal head was used to calculate the TMC joint's motion during flexion-extension and abduction-adduction. For every TMC joint condition and direction of motion, the data from the seven specimens were combined to calculate the mean and the $95 \%$ confidence interval. A mixed model was used to investigate differences in average ROM in both planes. To correct for the correlation between measurements on the same cadaver, a random cadaver effect was specified. Normality assumptions were 


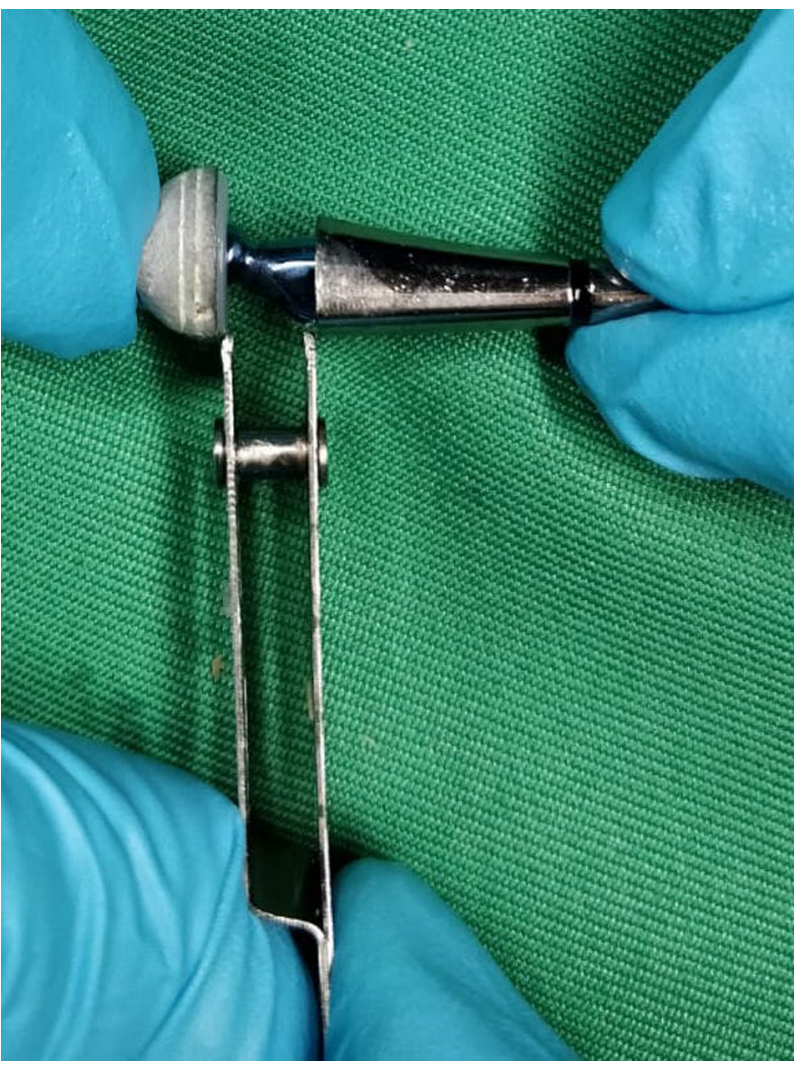

Fig. 2. The $5 \mathrm{~mm}$ resection width of the parallel saw blades corresponds exactly to the length of the shortest neck available for the trapeziometacarpal implant used in this study.

checked with QQ plots for the residuals. We compared all the conditions with the baseline situation and applied a false discovery rate correction to account for multiple tests. $P$ values $<0.05$ were considered significant.

\section{Results}

Outcome and statistical analysis of ROM in the flexionextension and abduction-adduction planes are provided in Figs. 3 and 4 respectively. Flexion-extension motion of the native TMC joint increased significantly after TJA with capsular release.
Without neck lengthening, the mean motion was $66.4^{\circ}$. This decreased progressively with incremental neck lengthening, and remained significantly higher than the ROM of the native joint for lengthening up to $6 \mathrm{~mm}$. Abduction-adduction motion increased slightly after capsular release and TJA, but did never differ significantly from the ROM of the native joint.

\section{Discussion}

TMC joint motion as measured with our experimental setup compares well with active motion of the TMC joint in living subjects. Using an optoelectronic device, Goubier et al. [9] found that the mean flexion-extension ROM was $41^{\circ}$ and the abductionadduction ROM was $51^{\circ}$ in 200 healthy hands.

All currently available TMC implants allow at least full physiological ROM [10]. According to our results, TJA with capsular release and restoration of normal thumb length results in significantly increased motion compared to the native joint. Like total hip arthroplasty, this could lead to intra-prosthetic impingement and dislocation at the extremes of motion [11]. Andrzejewski et al. [6] observed a 9.7\% dislocation rate in a series of 113 Maiia prostheses with unconstrained cups. They attributed this complication to their surgical technique that involved extensive release of all the capsular and ligament attachments around the TMC joint.

Progressive lengthening of the TMC joint implant up to $8 \mathrm{~mm}$ will again decrease the joint's ROM, but never to the point where ROM is significantly less than the native joint. However, it can be expected that such an extensive distraction has a negative impact on general thumb motion (including the metacarpophalangeal and interphalangeal joints) due to tensioning of the musculotendinous units around the thumb. Goubau et al. [12] could not find a correlation between the amount of TMC lengthening and the incidence of de Quervain's tenosynovitis after TMC TJA.

Our study has some limitations. First, the number of specimens is small. Second, our data are quite heterogeneous. This is probably due to the wide range of TMC joint ROM [9]. Third, the threshold for TMC joint lengthening before clinical repercussions develop is not known and needs further investigation. Fourth, capsular release does not only increase ROM of the TMC joint, but probably also causes longitudinal laxity when the thumb is pulled. Undue traction on the thumb in the immediate postoperative period could also contribute to implant dislocation. This hypothesis needs further investigation.

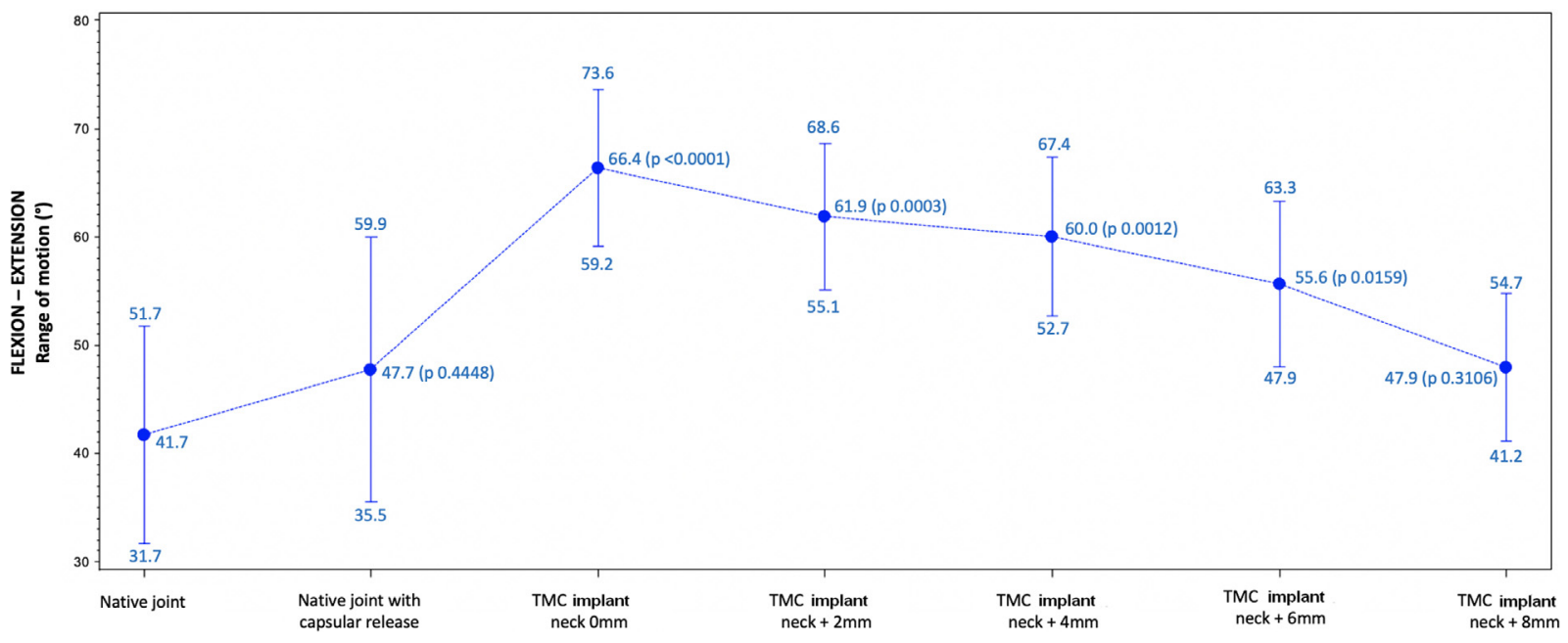

Fig. 3. Range of motion for flexion-extension. For every configuration of the TMC joint, mean, statistical significance and $95 \%$ confidence intervals are shown. 


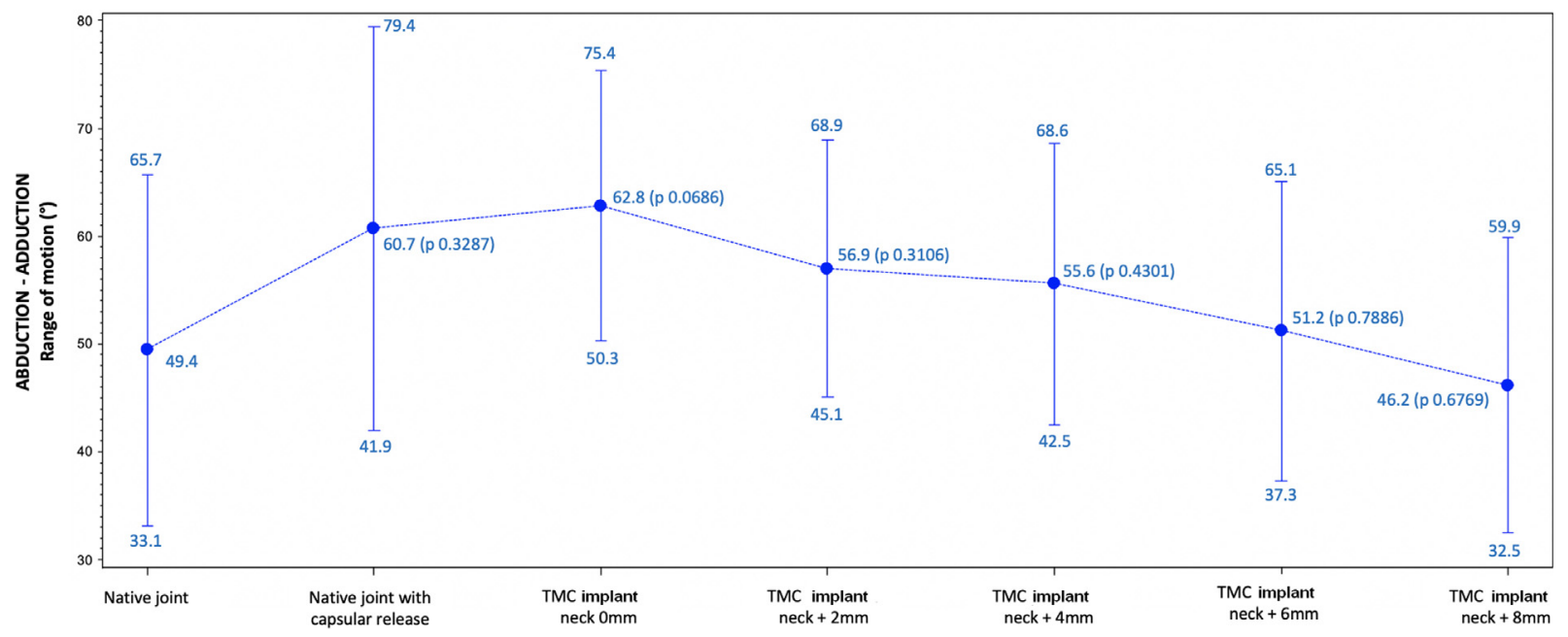

Fig. 4. Range of motion for abduction-adduction. For every configuration of the TMC joint, mean, statistical significance and 95\% confidence intervals are shown.

\section{Conclusion}

TMC TJA with complete release of the joint capsule significantly increases flexion-extension motion of the TMC joint. We assume that this could increase the probability of early dislocation during thumb movement, especially when the components are not well positioned and before any capsular healing has occurred. Further clinical research is needed to examine the importance of implant positioning and whether temporary postoperative immobilization can be beneficial.

\section{Disclosure of interest}

The authors declare that they have no competing interest.

\section{Funding}

The author(s) disclosed receipt of the following financial support for the research, authorship, and/or publication of this article: this research was supported by the Orthopedic Research Foundation Genk.

\section{Author statements} draft.

Bram Van Hove: methodology, investigation, writing - original

Jonas Vantilt: software, data curation.

Amber Bruijnes: formal analysis, project administration.

Pieter Caekebeke: writing - review \& editing.

Kristoff Corten: supervision.

Ilse Degreef: supervision.

Joris Duerinckx: conceptualization, methodology, investigation, writing - review \& editing.

\section{Human and animal rights}

The authors declare that the work described has not involved experimentation on humans or animals.

\section{Informed consent and patient details}

The authors declare that the work described does not involve patients or volunteers.

\section{References}

[1] Jager T, Barbary S, Dap F, Dautel G. Evaluation of postoperative pain and early functional results in the treatment of carpometacarpal joint arthritis. Comparative prospective study of trapeziectomy vs. MAIA prosthesis in 74 female patients. Chir Main 2013;32:55-62.

[2] Cootjans K, Vanhaecke J, Dezillie M, Barth J, Pottel H, Stockmans F. Joint survival analysis and clinical outcome of total joint arthroplasties with the ARPE implant in the treatment of trapeziometacarpal osteoarthritis with a minimal follow-up of 5 years. J Hand Surg Am 2017;42:630-8.

[3] Caekebeke P, Duerinckx J. Can surgical guidelines minimize complications after Maïa ${ }^{\mathbb{R}}$ trapeziometacarpal joint arthroplasty with unconstrained cups? J Hand Surg Eur 2018;43:420-5.

[4] Huang K, Hollevoet N, Giddins G. Thumb carpometacarpal joint total arthroplasty: a systematic review. J Hand Surg Eur 2015;40:338-50.

[5] Brauns A, Caekebeke P, Duerinckx J. The effect of cup orientation on stability of trapeziometacarpal total joint arthroplasty: a biomechanical cadaver study. Hand Surg Eur 2019;44(7):708-13.

[6] Andrzejewski A, Ledoux P. Maïa trapeziometacarpal joint arthroplasty: survival and clinical outcomes at 5 years' follow-up. Hand Surg Rehabil 2019;38:169-73.

[7] Crisco JJ, Halilaj E, Moore DC, Patel T, Weiss AP, Ladd AL. In vivo kinematics of the trapeziometacarpal joint during thumb extension-flexion and abductionadduction. J Hand Surg Am 2015;40:289-96.

[8] Mobargha N, Esplugas M, Garcia-Elias M, Lluch A, Megerle K, Hagert E. The effect of individual isometric muscle loading on the alignment of the base of the thumb metacarpal: a cadaveric study. J Hand Surg Eur 2015;41:374-9.

[9] Goubier JN, Devun L, Mitton D, Lavaste F, Papadogeorgou E. Normal range-ofmotion of trapeziometacarpal joint. Chir Main 2009;28:297-300.

[10] Semere A, Vuillerme N, Corcella D, Forli A, Moutet F. Results with the Roseland HAC trapeziometacarpal prosthesis after more than 10 years. Chir Main 2015;34:59-66.

[11] Hummel MT, Malkani AL, Yakkanti MR, Baker DL. Decreased dislocation after revision total hip arthroplasty using larger femoral head size and posterior capsular repair. J Arthroplasty 2009;24(Suppl. 6):73-6.

[12] Goubau JF, Goubau L, Goorens CK, van Hoonacker D, et al. De Quervain tenosynovitis following trapeziometacarpal ball-and-socket joint replacement. J Wrist Surg 2015;4:35-42. 